\title{
Generation Y's Information Needs Concerning Sharing Rides in Autonomous Mobility on Demand Systems
}

\author{
Alexandra König ${ }^{1, * \mathbb{D}}$, Christina Wirth ${ }^{2}$ and Jan Grippenkoven ${ }^{1}$ \\ 1 German Aerospace Center, Institute of Transportation Systems, 38108 Braunschweig, Germany; \\ jan.grippenkoven@dlr.de \\ 2 SRH Hochschule der Populären Künste (HDPK), 10783 Berlin, Germany; christina.wirth@t-online.de \\ * Correspondence: alexandra.koenig@dlr.de; Tel.: +49-531-295-3676
}

\section{check for}

updates

Citation: König, A.; Wirth, C.; Grippenkoven, J. Generation Y's Information Needs Concerning Sharing Rides in Autonomous Mobility on Demand Systems. Sustainability 2021, 13, 8095. https:/ / doi.org/10.3390/su13148095

Academic Editors: Yoram Shiftan,

Amalia Polydoropoulou,

Nikolas Thomopoulos and

Valentina Rappazzo

Received: 22 June 2021

Accepted: 17 July 2021

Published: 20 July 2021

Publisher's Note: MDPI stays neutral with regard to jurisdictional claims in published maps and institutional affiliations.

Copyright: (C) 2021 by the authors Licensee MDPI, Basel, Switzerland. This article is an open access article distributed under the terms and conditions of the Creative Commons Attribution (CC BY) license (https:// creativecommons.org/licenses/by/ $4.0 /)$.
Abstract: Empirical studies show that autonomous vehicles can contribute to sustainability goals when rides are shared. However, sharing rides with strangers in shared autonomous mobilityon-demand systems (SAMODSs) might impede the adoption of these systems. The present study addresses the research question whether a comprehensive information provision about fellow passengers could increase acceptability of the shared rides in SAMODSs. A discrete choice experiment $(N=154)$ assessed the potential of different levels of information on fellow passengers: (1) no information, (2) name, (3) picture, (4) rating, (5) combination of name, picture and rating. The results show that the overall compensation demands for sharing a ride was a reduction of approximately $25 \%$ of the nonshared reference price. The provision of detailed information about fellow travelers proved beneficial for reducing the compensation demands of travelers while the provision of a name only resulted in higher compensation demands. A significant effect of the fellow passengers' gender indicated that male gender information was related to a higher refusal rate than female gender information. This was particularly relevant when only names were presented. The study provides first empirical insights into the psychological factors concerning the emerging trend of shared mobility.

Keywords: ridesharing; user requirements; information needs; trust; gender perspective; perceived safety; automated and connected transport

\section{Introduction}

\subsection{Shared Autonomous Mobility on Demand Systems}

Driverless vehicles of SAE level 5 [1] that are capable of self-driving under all conditions [2] are predicted to be a promising future because they will most probably contribute to a transition towards a more efficient, safe and convenient transport system [3-5] and are supposed to fundamentally change the way we travel and live [6]. Studies suggest that the value of time in terms of willingness to pay for saving travel time might decrease because people can use the time in the autonomous vehicle (AV) for other purposes than driving [6]. Depending on the scenario, the penetration of AV traffic will either dramatically rise or significantly decrease [4,5,7]. Privately-owned autonomous vehicles are expected to contribute to an increase in vehicle kilometres travelled (VKT) and, consequently, higher local emissions: "If autonomous vehicles turn out to be mainly privately owned, the resulting increase in road traffic will negate the time savings" [6] (p. 9f). In contrast, shared autonomous vehicles will contribute to a decrease in VKT, parking spaces and emissions $[4,5,7]$. Thus, research requests to increase the occupancy rate of AV by ridesharing, which is considered as an essential prerequisite for reducing the traffic volume [8-12]. Lavieri and Bhat (2018) stated "there is growing evidence that ridesharing will be a key element to ensure a sustainable future to urban transportation in an AV future." [10] (p. 29). Ridesharing in autonomous vehicles can be realized by using a demand-responsive 
operation scheme of so-called mobility-on-demand systems that allows for flexible and highly dynamic adoptions of the route according to the passengers' requests [13]. The combination of autonomous driving technology and mobility-on-demand systems is considered to be a beneficial synergy for reaching sustainability goals [3]. The paper defines shared autonomous mobility-on-demand systems (SAMODSs) as autonomous, shared public transport services with flexible routing, which implies additional journey time due to the pick-up and drop-off of other passengers. See [14] for a more detailed description of different ownership and usage scenarios of shared autonomous vehicles.

The interest in SAMODSs, also called SAMS [15], is reflected in the considerable number of simulation studies assessing the economic and ecological effects of shared driverless mobility-on-demand systems [16] as well as impacts on transport systems and traffic [9,17-19]. From the passenger's perspective, the ridesharing aspect of mobility-ondemand systems is likely to be a crucial point for users' assessment of the service because the sharing of rides implies detours for passengers [20]. Furthermore, the absence of a driver in SAMODSs was shown to be related to higher safety concerns [21,22]. Accordingly, Krueger, Rashidi, and Rose (2016) state that the adoption of SAMODSs "[ ... ] heavily relies on user acceptance, as users must be willing to spend some time with a stranger in the confined space [... ]." [23] (p. 345).

Giving regard to the expected benefits of SAMODSs for reaching sustainability goals in transport, the factors that affect the willingness of future users to adopt these systems must be considered in the design of these systems. The present study aims to identify facilitating factors for travellers' willingness to share rides with strangers in SAMODSs. More specifically, the study's objective is to assess the effectiveness of information provision about fellow travellers to improve travellers' willingness to use the service.

\subsection{Literature Review}

Scientific literature on the acceptance of self-driving public busses (SDPB) sharply increased in the last years [22,24-26]. These studies prove the impact of attitudinal factors, such as the perceptions of safety on the acceptance of the new autonomous public bus system (e.g., [24]). The findings imply a rather controversial perception of potential users on the technology. On the one hand, studies by [22,27] report a high acceptability of self-driving vehicles for public transport use. On the other hand, several studies found considerable concerns among potential users towards the emergence of driverless vehicles and the transformation of public transport system [28,29]. The interest in autonomous vehicles for public transport is reflected by the number of pilot projects that tested autonomous public transport in naturalistic settings, like in Berlin, Germany [30] (Nordhoff et al., 2018), Espoo, Finland [22] or Lausanne, France [27]. However, it should be noted that the number of pilot studies in open and mixed traffic is quite limited, and thus, empirical evidence concerning the users' acceptance is restricted to specific characteristics of the pilots, like slow velocity and the presence of a trained fallback driver. In contrast, the use case of SAMODSs is challenged with additional degrees of freedom because the operation scheme depends on flexible on-demand routing rather than fixed schedules. However, as a consequence to their novelty, there are only few empirical studies addressing the users' acceptance of SAMODSs. As one of the first studies addressing the use case of SAMODSs, Fraedrich, Cyganski, Wolf, and Lenz (2016) found low acceptability of respondents for the so-called Vehicle on Demand. About two thirds of the respondents showed slight or strong unwillingness to use such shared autonomous transport systems [21]. Safety concerns and low perceived performance expectancy of SAMODSs were provided as possible explanations by the authors [21]. Accordingly, Lavieri and Bhat (2018) found the adoption of SAMODSs to be strongly associated with the increased travel time due to the access and egress of further travellers [10]. The study furthermore showed that privacy and security concerns discouraged participants to choose shared rides. The results of the study further indicated that sharing trips with strangers seems to be less aversive for commute trips than for leisure trips [10]. 
A stated choice survey by Krueger, Rashidi and Rose (2016) found the service attributes waiting time, travel time and costs to be important determinants of the willingness to use SAMODSs [23]. The findings are supported by a discrete choice experiment that proved a strong effect of travel time and the detour, caused by the pick-up and drop-off of passengers, on participants' willingness to share rides in SAMODSs [31]. The authors conclude that a pricing system of SAMODSs should pay attention to ride-specific travel time and detours in order to attract travellers to choose the shared option [31].

Concerning the individual-specific determinants of acceptability, the above-mentioned stated choice survey by Krueger, Rashidi, and Rose (2016) found individuals between 24 and 29 years to be the most open to choose the shared ride in SAMODSs [23]. Thus, in line with similar studies, it can be assumed that younger generations are likely to be the first users of such services [32,33]. König and Grippenkoven (2020) found that a higher discount is needed to attract women to choose the shared ride compared to men [31]. The finding is supported by the results of Lavieri and Bhat (2018) who found a reduced likelihood of women to choose the shared option [9]. This finding might be explained by another finding, that women are supposed to have stronger safety concerns in driverless bus shuttles than men [34].

The findings of [23] were complemented by a recent study that used a stated preference experiment to assess users' willingness to share rides with strangers in shared autonomous vehicles [35]. The study found a considerable reluctance of women to choose the shared option when sharing the ride with a male co-traveller [35]. The authors thus encourage research and policy to identify solutions for enhancing women's experiences with shared automated transport services [35].

Drawing on studies that address ridesharing systems, like BlaBlaCar [36], can provide indications for the underlying determinants of sharing rides in SAMODSs. These studies recurrently report individuals' unwillingness and resistance to share rides with strangers due to the need for sufficient personal space, the possibility of having a negative social interaction, distrust as well as safety and security concerns [10,37-39]. Morales Sarriera et al. (2017) also report on riders' feelings of prejudice towards other passengers due to their race or socio-economic class [38]. Substantial discrimination in the context of ridesharing was also reported in a recent experimental study by [40]. They found empirical evidence for the discrimination of Turkish men in a study with German users of a ridesharing service [40]. The unwillingness to share rides with strangers is most likely associated with a lack of trust [37].

Providing information about fellow passengers might possibly enhance trust [38]. The willingness to share rides correlated with the name recognition of the fellow travellers in a study by [41]. Thus, travelling with a friend of a friend or a member of their university resulted in a higher willingness to share the trip than travelling with an unknown person. Bansal et al. (2016) comes to similar conclusions as they found that more than half of the respondents are willing to share the ride with a friend of a Facebook friend although he or she was not directly known to them [42]. Moreover, Siddiqi and Buliung (2013) suggest providing various personal information such as name, age, gender and occupation about other passengers for ridesharing service [43]. They also recommend providing a peer-reviewed reputation system [43]. However, for the use case of SAMODSs, empirical findings are lacking regarding the question whether information provided about fellow travellers might reduce feelings of insecurity and increase the willingness to share rides with strangers.

\subsection{Research Objectives}

The present study aims to examine the effect of four potential determinants on the willingness to share rides with fellow travellers in SAMODSs and their potential interplay: (1) travel time, (2) degree of vehicle automation, (3) quality of information on fellow passengers (e.g., picture, name or rating) and (4) gender of the fellow passenger. In particular, the study addresses the following research questions: 
- RQ1: How far does the provision of information about fellow travellers affect the willingness to share rides in mobility-on-demand systems?

- RQ2: Which information on fellow passengers (e.g., picture, rating etc.) proves especially relevant for increasing travellers' willingness to share rides in mobility-ondemand systems?

- RQ3: Do the information needs of travellers increase when no driver is present in autonomous mobility-on-demand systems?

- RQ4: Does the length of the trip influence the relevance of provided information about fellow passengers for travellers' willingness to share the trip? Figure 1 provides a schematic overview over the research questions and the expected relationships between the variables. The study at hand thereby focuses on a specific potential user group-Generation Y, which comprises persons born between 1981 and 1999, also called millennials [44]. This specific cohort is expected to be more likely to adopt mobility-on-demand like Uber services [32], tend to favor sharing-based service models over private ownership [33] and show greater openness towards autonomous mobility services [21].

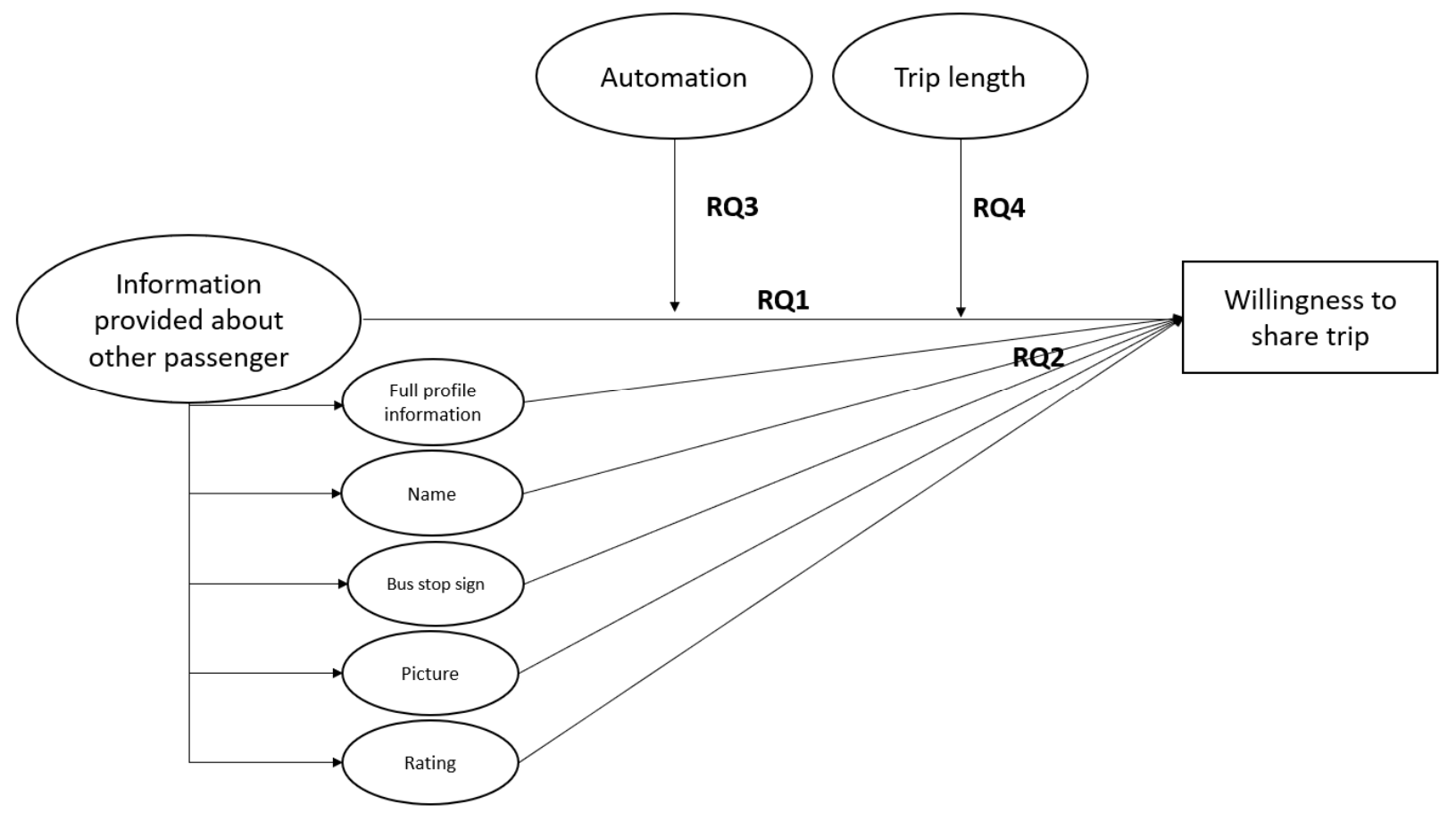

Figure 1. Schematic representation of the research questions. Dependent variable is represented as a rectangle, predictors and mediators as ellipses.

\section{Materials and Methods}

\subsection{Study Design}

A discrete choice experiment (DCE) was used for approaching the research questions [45]. DCE are frequently used in transportation research [46] and has been applied to the assessment of acceptability of autonomous vehicles before [47,48].

The dependent variable was the amount the respondents are willing to spend for a shared ride in an autonomous mobility-on-demand system compared to a nonshared ride. The willingness to share rides was realized as the Willingness to Accept (WTA). The WTA is defined as the amount a person is willing to accept to abandon a good or to put up with something negative and thus is linked to the concept of willingness to pay (WTP) that refers to the maximum price an individual is willing to pay for a product of service [49]. The WTA was assessed by the amount respondents are willing to pay for a shared ride in an SAMODS compared to the reference of a nonshared ride. 
Inspired by studies that studied the effect of the presentation of different information on the acceptance of ridesharing, like pictures [10,38], name [43] or a rating [38,39,43], the study used quality of information as the first independent variable. Quality of information had five levels: (A) bus stop sign, (B) name, (C) picture, (D) rating and E) full profile information as a combination of the levels name, picture and rating (Figure 2). Further independent variables were (1) gender: information on the gender of the further traveller, (2) travel time: the length of the ride with two levels: $14 \mathrm{~min}$ vs. $25 \mathrm{~min}$ and (3) automation: the level of vehicle automation: with driver vs. driverless (Figure 1). The profile pictures of the female and male fellow travellers were used from the CHICAGO FACE DATABASE with a medium rated attractiveness [50]. Typical German female (Michaela) and male (Andreas) names were chosen for the SP experiment. A mixed design was used, consisting of the between-subjects factor automation and the within-subject factors quality of information, travel time and gender of the fellow traveller.

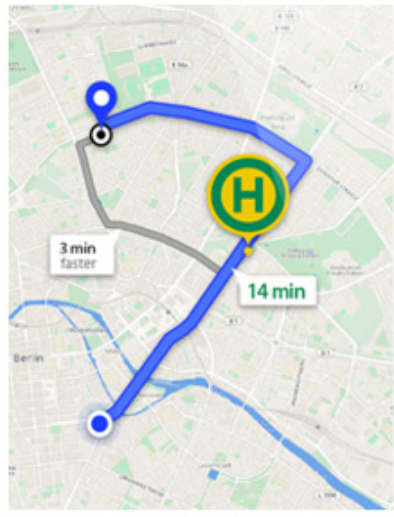

bus stop sign

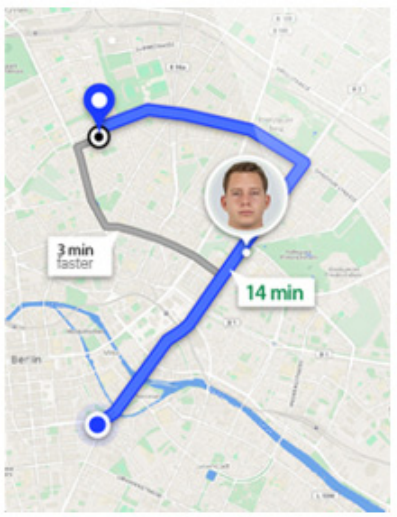

male picture

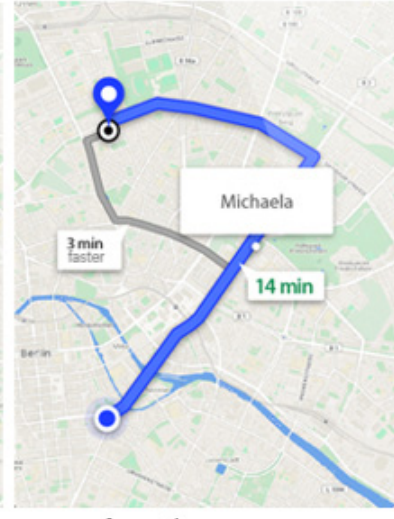

female name

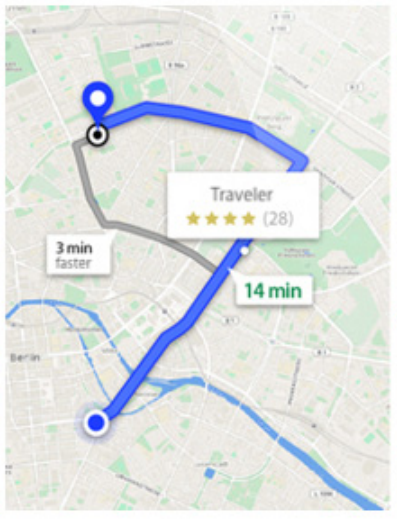

rating

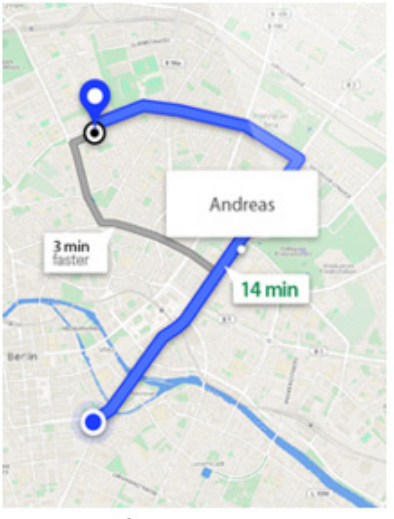

male name

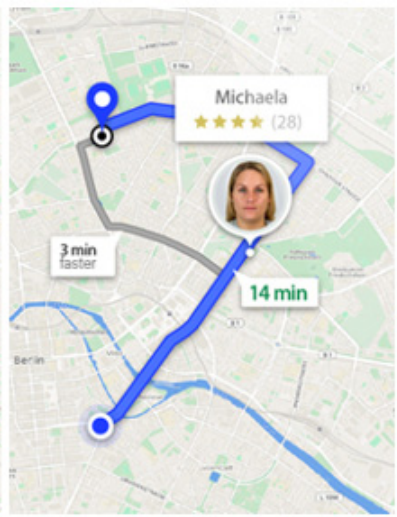

full female profile information

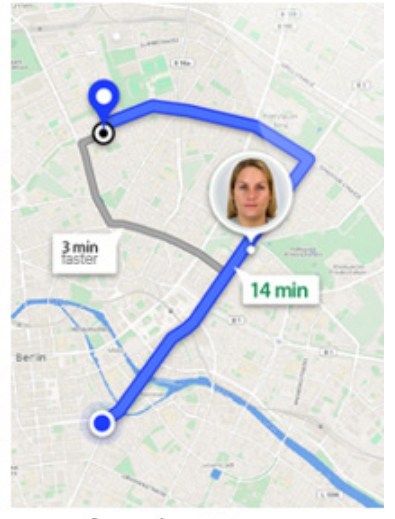

female picture

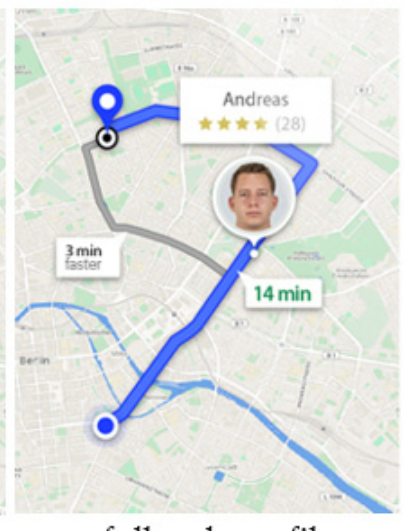

full male profile information

Figure 2. Levels of the variable quality of information.

Two alternative routes were presented to the study participants: (1) a direct, nonshared ride and (2) a shared ride implying a detour caused by the access of a fellow traveller (Figure 3). The shared scenarios were created based on the assumption that the respondents share about $50 \%$ of travel distance together. For each scenario, the study participants were asked to imagine a ride with only one fellow passenger. In order to assess the WTA for shared rides, the participants were asked to specify the maximal amount of money they would be willing to pay for the shared ride (right) in comparison to the nonshared ride (left). The fictional currency $ð$ was used for avoiding anchoring effects of current prices for transportation. Respondents were further given the chance to choose the alternative "I would rather not choose option 2" as an opt-out alternative. 

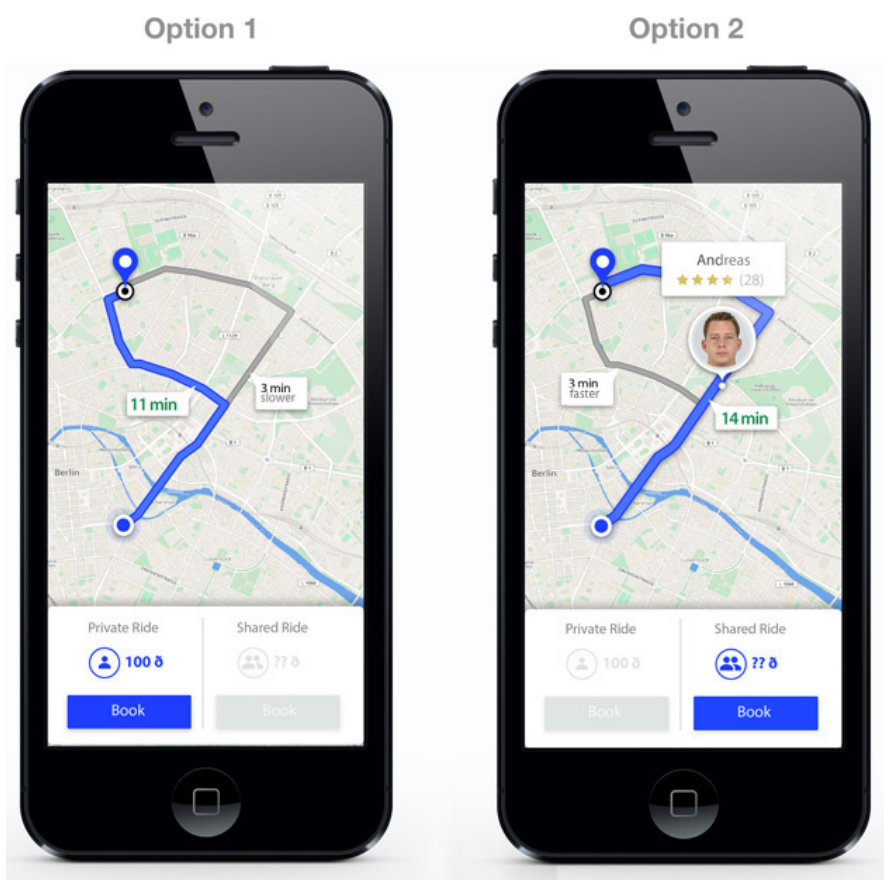

Figure 3. Example of a choice set consisting two alternatives: left: nonshared ride, right: shared ride with full information on fellow traveller.

\subsection{Procedure}

The study was performed as an online survey using the software SosciSurvey [51]. The participants were recruited via social media platforms during August and September 2019. The respondents were randomly assigned to either the scenario based on a mobility-on-demand system with or without a driver. The participants were introduced to the study subject by a textual and graphical explanation regarding the vehicle concept, which was introduced as an 8-seater. Following a between-subjects design, half of the participants were introduced to the operational concept of an autonomous mobility-ondemand system whereas the other half was introduced to the concept with driver. They were then introduced to the task of determining the maximum price they are willing to pay to accept sharing rides with strangers. For this purpose, two examples were presented to the participants. Right before the start of the choice tasks the scenario was presented to the participants. The scenario was framed as a ride in an urban setting with the objective to meet a friend.

The participants were asked to respond to 16 choice tasks as presented in Figure 3. The order of the choice tasks varied between the participants. At the end of the questionnaire, the respondents were asked to answer several sociodemographic questions and questions regarding their mobility behavior. Furthermore, trust in fellow travellers was measured with the help of three items adapted from a questionnaire study concerning ridesharing: "I would trust fellow passengers", "I believe I would have concerns regarding my safety when sharing a ride" and "For me, sharing rides with fellow passengers is not accompanied with risks" [37]. A five-point Likert scale was used for answering the items.

\subsection{Data Analysis}

Data were analysed with the help of the statistical software SPSS. Only those respondents of the survey were included that were aged between 18 and 39 and thus were assigned to the Generation $Y$ [52]. Respondents were excluded from data analysis ( $n=39)$ when they did not correctly remember the introduced scenario (Do you remember which of the following scenarios was introduced to you?).

For data analysis, the format of the dataset was restructured from wide to long format. For computing the WTA, the amount that participants were willing to pay for a shared ride 
( $\left.ð_{\text {shared }}\right)$ was related to the default price of the nonshared ride ( $\left.ð_{\text {nonshared }}\right)$. The resulting

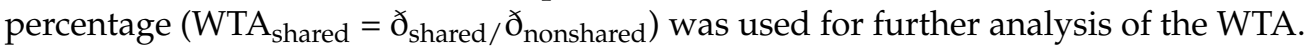

\subsection{Participants}

The final sample $(N=154)$ was characterized by a mean age of 26.5 years $(S D=4.4$ years). The sample consisted of more women $(n=95,61.7 \%)$ than men $(n=57,37.0 \%$, rest missing). The majority of respondents were still in education (57.1\%). A share of $31.8 \%$ worked full-time and another $6.5 \%$ in part-time. As shown in Table 1 , the respondents were well educated, with more than $50 \%$ holding a university degree. The net household income was comparable to the general population aged 18-25 (1.779 $€$ ) and 25-35 years (2.965€) [53]. A total of $94.8 \%$ had a driver's license $(n=146)$. The bike was the most often used transport means on a regular basis for $48.7 \%$ of respondents $(n=75)$.

Table 1. Sociodemographic characteristics of the sample $(N=154)$.

\begin{tabular}{ccc}
\hline Sociodemographic Variable & Characteristics & n (\%) \\
\hline Size of residence & $<5.000$ & $17(11.0)$ \\
(number of inhabitants) & $5.000-50.000$ & $19(12.3)$ \\
& $50.000-500.000$ & $72(46.8)$ \\
& $>500.000$ & $45(29.2)$ \\
& Missing & $1(0.6)$ \\
Highest educational level & Hecondary school certificate & $1(0.6)$ \\
& Vocational training & $42(27.3)$ \\
& University degree & $9(5.8)$ \\
& PhD-degree & $98(57.1)$ \\
Job status & Missing & $2(1.3)$ \\
& Full-Time & $1(0.6)$ \\
& Part-Time & $49(31.8)$ \\
& In education & $10(6.5)$ \\
& Temporary out of work & $88(57.1)$ \\
(at last once a week) & Unemployed & $1(0.6)$ \\
& Missing & $1(0.6)$ \\
& $<1.000 €$ & $5(3.2)$ \\
Net household income & $1.000-1.500 €$ & $57(37.0)$ \\
& $1.500-2.000 €$ & $25(16.2)$ \\
& $2.000-3.000 €$ & $17(11.0)$ \\
& $>3.000 €$ & $32(20.8)$ \\
& Missing & $15(9.7)$ \\
& Car & $8(5.2)$ \\
& Bram/subway & $24(15.6)$ \\
& Train & $35(22.7)$ \\
& Bike & $49(31.8)$ \\
& & $24(15.6)$ \\
& $75(48.7)$ \\
\hline
\end{tabular}

\section{Results}

In the following, the results of the data analysis are presented for the effects of the four independent variables: travel time, degree of vehicle automation, quality of information on fellow passengers (e.g., picture, name or rating) and gender of the fellow passenger.

\subsection{Refusal Rate of Shared Rides}

First, data was analyzed concerning the rate of respondents that rejected the shared rides by indicating "I would rather not choose option 2 ". The refusal rate was implemented as the percentage of shared rides that were rejected by the respondents. The overall refusal rate across all levels of information provision was $2.7 \%(S D=1.6 \%)$. As shown in Table 2 , the mean refusal rate differed depending on the amount of information given about the other passengers. The refusal rate was the highest under the condition of 25min_name_male with a refusal rate of $7.1 \%(S D=0.26 \%)$ and the lowest for the condition 14min_all_female 
with not a single rejection ( $0 \%)$. The descriptive analysis reveals that the share of rejected rides is slightly higher for longer rides (Mean refusal rate $_{25 \mathrm{~min}}=3.7 \%, S D=0.19 \%$, Mean refusal rate $_{14} \min =1.7 \%, S D=0.13 \%$ ).

Table 2. Mean refusal rate in percent and standard deviation in parentheses according to information quality (bus stop sign, name female, name male, picture female, picture male, rating, full profile information female and full profile information male) and travel time (14 $\mathrm{min}$ vs. $25 \mathrm{~min}$ ).

\begin{tabular}{|c|c|c|c|c|c|c|c|c|c|c|}
\hline \multicolumn{11}{|c|}{ Level of Quality of Information } \\
\hline & & BSS & N_F & N_M & P_F & P_M & $\mathbf{R}$ & F_F & F_M & Total \\
\hline $\begin{array}{l}\text { Share of } \\
\text { rejected shared }\end{array}$ & $14 \mathrm{~min}$ & $1.9(0.14)$ & $1.9(0.14)$ & $4.5(0.21)$ & $1.3(0.11)$ & $2.6(0.16)$ & $0.6(0.08)$ & $0.0(0.00)$ & $0.6(0.08)$ & $1.7(0.13)$ \\
\hline rides in $\%$ & $25 \mathrm{~min}$ & $5.2(0.22)$ & $1.3(0.11)$ & $7.1(0.26)$ & $1.9(0.14)$ & $3.2(0.18)$ & $3.9(0.19)$ & $3.2(0.18)$ & $3.2(0.18)$ & $3.7(0.19)$ \\
\hline
\end{tabular}

Note. $B B S=$ bus stop sign, $N_{-} F=$ name female, $N_{-} M=$ name male, $P \_F=$ picture female, $P \_M=$ picture male, $R=$ rating, $F \_F=$ full profile information female, $F_{-} \mathrm{M}=$ full profile information male.

For modeling the effect of the independent variables on the binary dependent variable refusal rate, a Generalized Linear Mixed Model (GLMM) was computed with the statistical software $R$ using the function glmer of the package lme4 [54]. GLMM allow for the estimation of longitudinal data-like repeated observations in the case of the study-and are applicable to non-normal data [55]. The categorial variable information degree was transformed in dummy-coded variables with the category bus stop sign as baseline.

For model 1 with main effects only, the regressors travel time, gender information and the two dummy variables for full profile information and rating revealed significance in the model (Table 3). The degree of vehicle automation and the information levels name and picture failed to reach significance within the model. The model concerning the null hypothesis revealed an intraclass correlation (ICC) of. 608, indicating that more than 60 percent of variation in the respective variables is between people and the answers given by people in the repeated measures were rather stable [56].

To test the effects of the moderator variables on the dependent variable, an interaction model was computed. For the interaction model, interaction terms were included based on the assumptions guided by the research questions (Section 1.3) if they increased model fit. Excluding the variable degree of automation from the model, increased model fit. The final interaction model (Table 3, right) had a better model fit than model $1(-2 \operatorname{LLog}=-193.3$, $\mathrm{AIC}=404.5, \mathrm{BIC}=456.8$ ). Thus, it can be concluded that the interaction model is more suitable to reflect the data.

As shown before in Model 1, travel time had a significant effect on the refusal time in a way that a one unit increase in travel time was associated with a 1.148 unit increase in the expected log odds of the refusal rate $(p<0.001)$. In contrast to model 1 , the predictors rating, full profile and gender information become less important in the interaction model. The presentation of full profile information significantly decreased the probability of refusing a shared ride $(\exp (\beta)=0.407, p=0.050)$. In contrast, providing information on the name of the fellow passenger increased the refusal rate $(\exp (\beta)=16.44, p=0.024)$. The presentation of a male name increased the respondents' unwillingness to share rides while the presentation of a female name improved the willingness to share rides and was linked to a reduced the refusal rate as shown by a marginally significant effect $(\exp (\beta)=0.256, p=0.087)$. The model further proved the relationship between the refusal rate and the presentation of gender information in a way that male gender information was related to a higher refusal rate than female gender information, $(\exp (\beta)=0.394, p=0.043)$. 
Table 3. Comparison of the Generalized Linear Mixed Models.

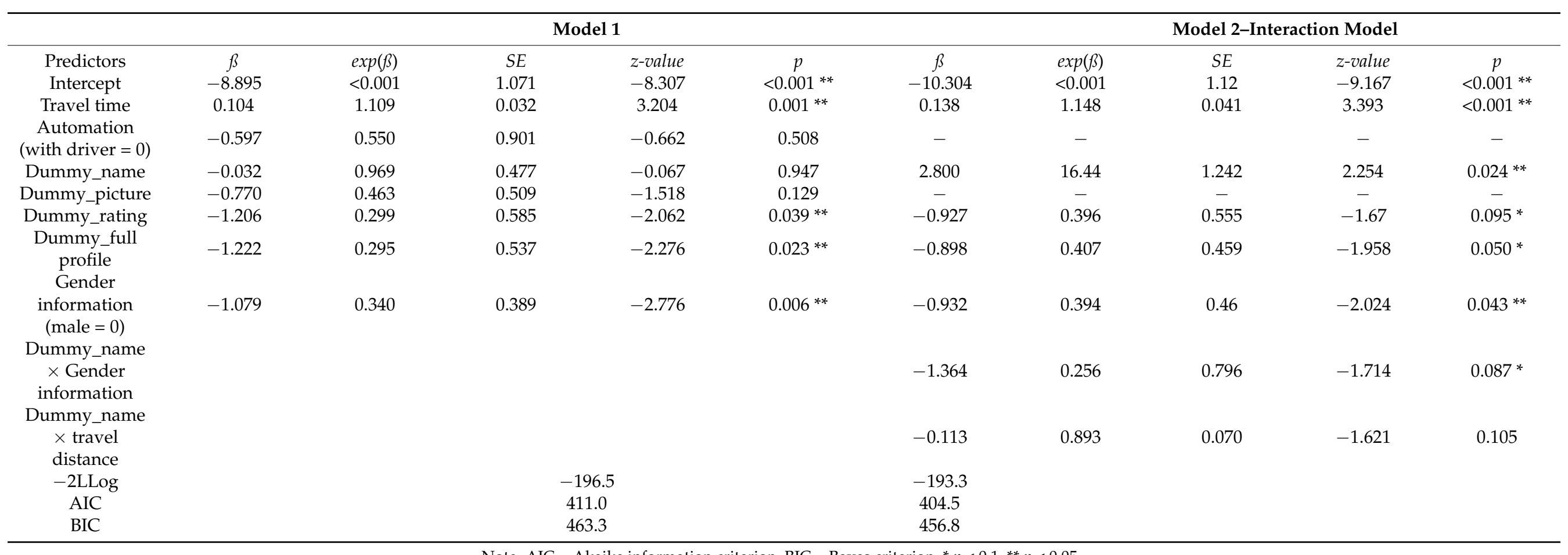




\subsection{Willingness to Accept}

Disregarding the independent variables, the overall WTA was $73.73 \%$ of the nonshared reference ride. The variance of the WTA was high as shown by $S D=17.17 \%$.

The descriptive analysis reveals that the WTA is slightly higher for shorter rides of $14 \min (M=74.17 \% ; S D=19.02 \%)$ than for longer rides of $25 \min (M=68.91 \% ; S D=24.03 \%)$. As shown in Figure 4, the mean WTA differed according to the quality of information presented about the fellow passenger. The mean WTA was the lowest under the condition of $25 \mathrm{~min} \_$bus stop sign $(M=67.12 \%, S D=25.63 \%)$ and the highest for $14 \mathrm{~min} \_$full profile information $(M=76.14 \%, S D=17.20 \%)$.

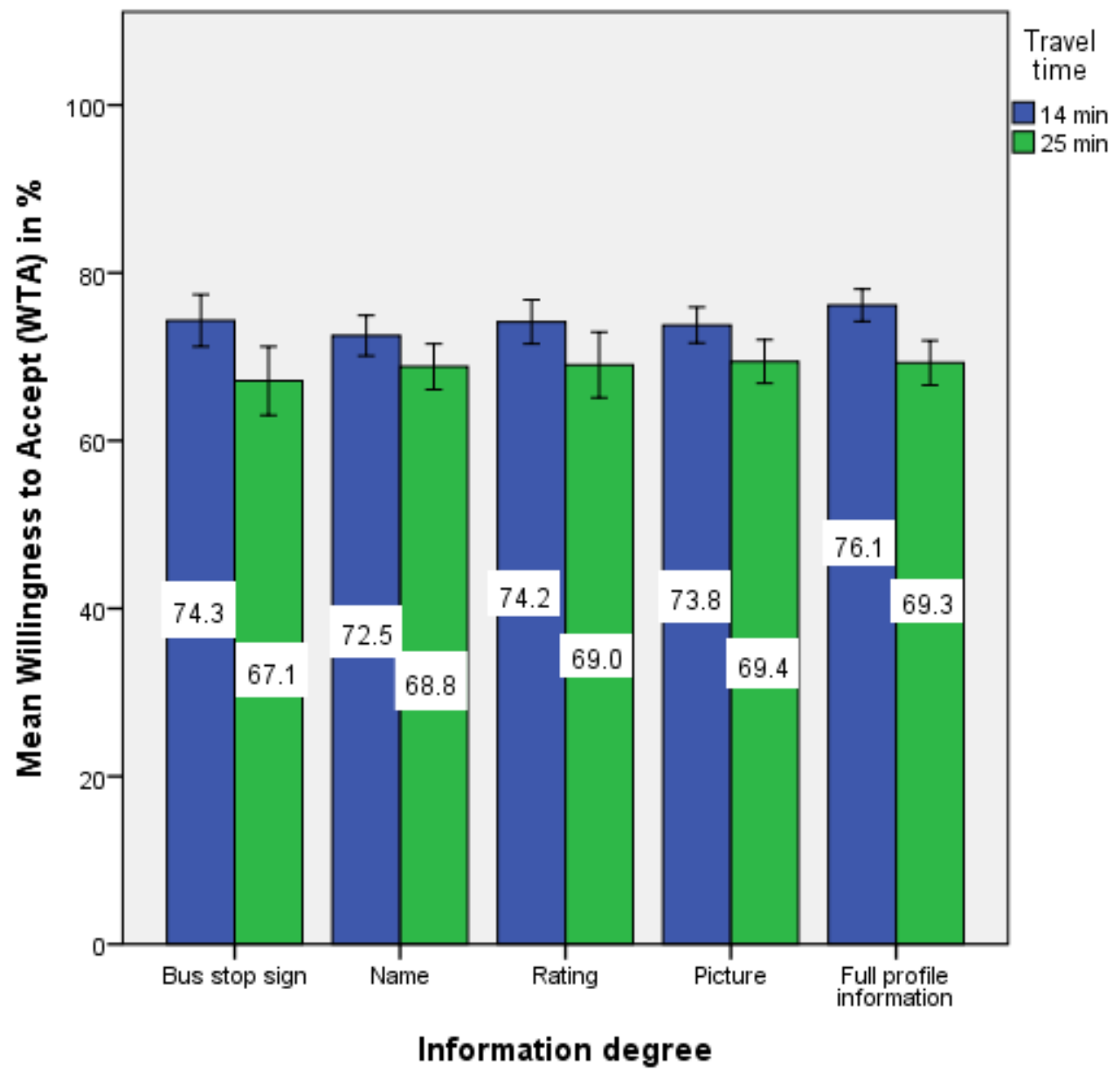

Figure 4. Mean Willingness to Accept according to information degree and travel time. Whiskers represent confidence intervals.

With regard to gender information, a significant effect of the gender of the fellow passenger on the WTA was shown under the condition name $(t(614)=-1.859 ; p=0.064$, Figure 5). In more detail, it was shown that the presentation of the female name was related to a higher WTA $(M=72.40, S D=20.38)$ than the presentation of a male name $(M=68.96$, $S D=25.22)$. 


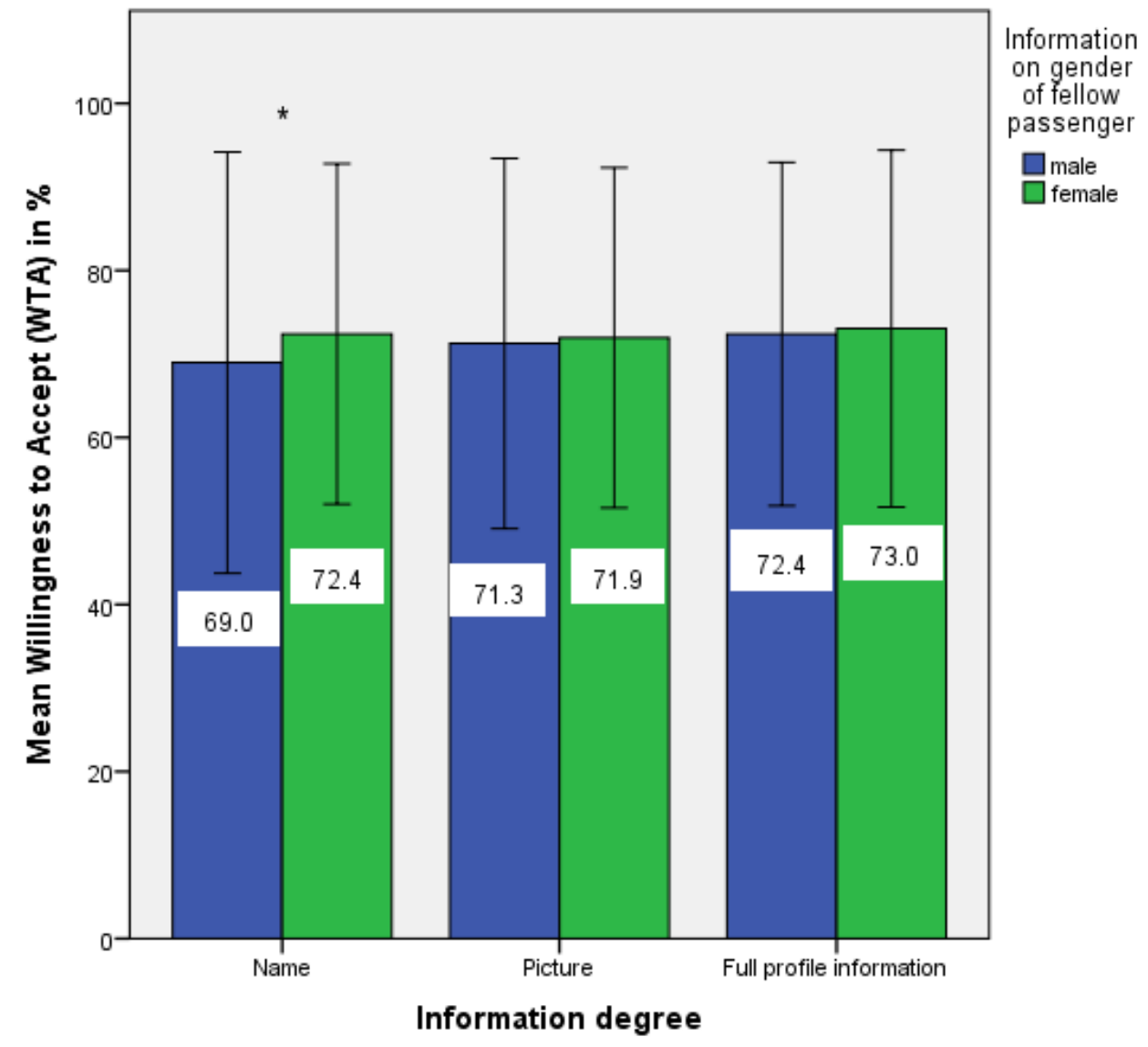

Figure 5. Mean Willingness to Accept according to information degree and gender of fellow passenger. Whiskers represent $+/-1 S D, * p<0.1$.

A mixed-effects model was computed using the function lmer of the lme4 package of $R$ [55]. The categorial variable information degree was transformed in dummy-coded variables with the category bus stop sign as baseline. First, a model with main effects only was computed. Then, interaction terms were added to the model.

As shown in Table 4, regression analysis proved a highly significant effect of travel time on WTA $(t(9)=-0.519 ; p<0.001)$. Respondents showed higher WTA values when trip duration was short $(M=74.17 \% ; S D=19.02 \%)$ than for longer rides $(M=68.91 \%$; $S D=24.03 \%)$.

Concerning the effect of the degree of vehicle automation the regression analysis found a marginally significant effect in the model in a way that vehicle automation was linked to a lower WTA $(t(148.99)=5.093 ; p=0.066)$, thus indicating that respondents require less compensation when the vehicle is autonomous.

Information on the gender of the fellow passenger marginal significantly predicted the WTA $(t(9.00)=1.459, p=0.062)$. According, as shown by $\exp (\beta)$, the WTA increased by 10.794 when female instead of male gender information were presented.

Subsequently, interaction terms were added to the interaction model. The model was chosen that reached the best model fit $(-2 \mathrm{LLog}=9921.6, \mathrm{AIC}=19,865, \mathrm{BIC}=19,929)$. The change in -2 LL between the two models ( - LLogModel $1=-9923.2,-2$ LLogModel2 $=9921.6)$ was highly significant $(p<0.05)$ according to the critical values of the chi-square distribution [48]. 
Table 4. Comparison of the Linear Mixed-Effects Models.

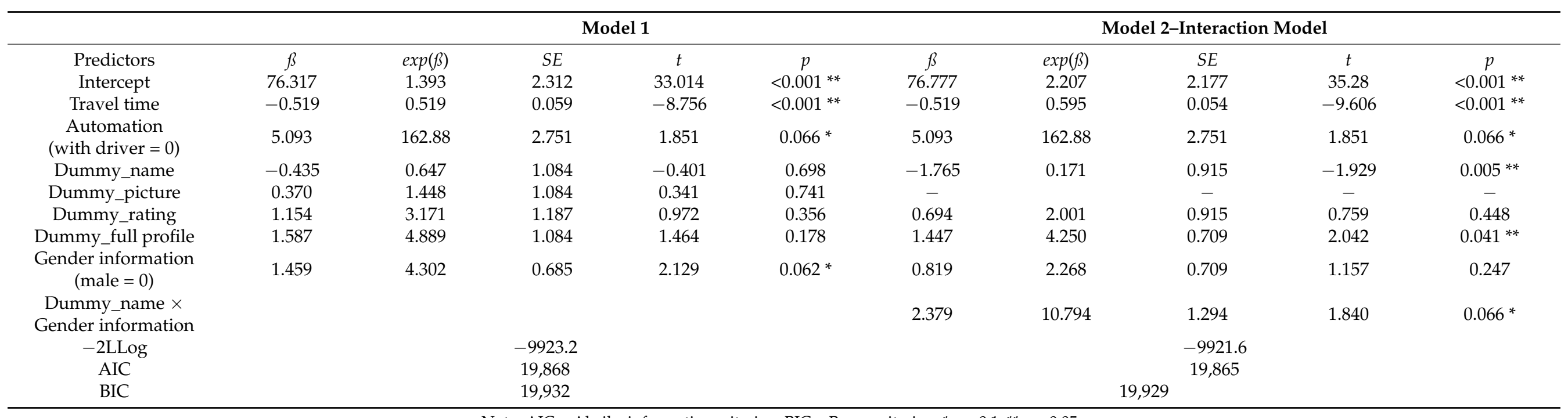

Note. AIC $=$ Akaike information criterion, BIC $=$ Bayes criterion, ${ }^{*} p<0.1,{ }^{* *} p<0.05$. 
In the interaction model, the main effect of degree of automation was still marginally significant $(p=0.066)$. Interactions terms with degree of automation and other factors did not reach significance and did not improve model fit and thus were not included in the revised model.

Travel time revealed a highly significant negative effect on the WTA $(\beta=-0.519$, $p<0.001)$. As shown by $\exp (\beta)=0.595$, a one unit increase in travel time was associated with a 0.595 unit decrease in the expected log odds of the WTA $(p<0.001)$.

Quality of information revealed to be a significant predictor only for full profile information $(t(2258.99)=1.447 ; p=0.041)$. The regression analysis thus showed that the WTA significantly increased $(\exp (\beta)=4.250)$ when full profile information was presented compared to the baseline condition bus stop sign. On the contrary, the presentation of information on the name of the fellow traveler revealed a significant and negative effect on the WTA $(\beta=-1.765, p=0.005)$, showing that information concerning the name alone increased the compensation demands. An interaction effect with the gender of the fellow traveller with the presentation of a name was shown $(t(2258.99)=2.379 ; p=0.066)$. In comparison to model 1, the predictor gender information became less important in presence of the interaction term name $x$ gender information in the interaction model.

An ANOVA with repeated measures proved a significant interaction effect of gender information and gender of the respondents under the condition picture for the longer ride $(F(1,142)=5.866, p=0.017)$ but not for the shorter ride of $14 \mathrm{~min}(F(1,144)=2.035$, $p=0.156$ ). As shown in Figure 6 (top left), for the longer ride, both women and men tend to show higher WTA values confronted with a shared ride with a member of the opposite gender. Being female and confronted with a male picture resulted in a higher WTA $(M=72.70, S D=19.36)$ for the 25 -min ride than when being confronted with a female picture $(M=69.31, S D=20.80, F(1,89)=6.273, p=0.014)$ whereas the effect was not significant for male respondents $(F(1,53)=1.264, p=0.266)$.
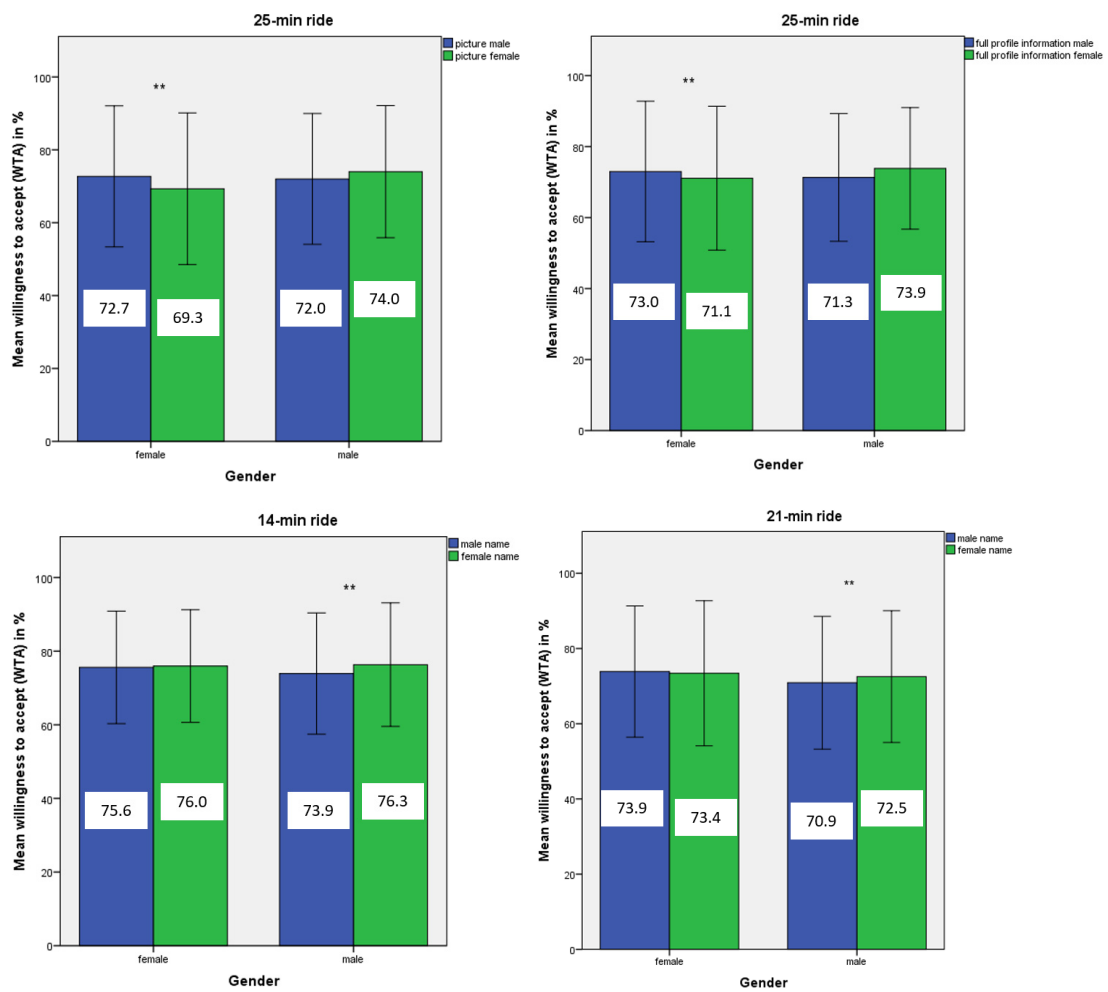

Figure 6. Mean Willingness to Accept (WTA) according to quality of information, gender information and respondent's gender. (Top left): 25-min ride under the condition Picture, (Top right): 25-min ride under the condition full profile information, (Bottom left): 14-min ride under the condition Name, (Bottom right): 25-min ride under the condition Name. Whiskers represent $+/-1$ standard deviation, ${ }^{* *} p<0.05$. 
Under the condition name, a marginally significant interaction effect of gender information and own gender was shown for the shorter ride $(F(1,142)=3.299, p=0.071)$ as well as the longer ride $(F(1,138)=3.266, p=0.073)$. In more detail, it was shown that men, who were presented to a female name, indicated a higher WTA for the shorter ride $(M=76.33, S D=16.77)$ than when viewing a male name $(M=73.92, S D=16.48$, $F(1,52)=4.763, p=0.034$, Figure 6 , bottom left). The same inter-relation was shown for the longer ride $(F(1,52)=4.510, p=0.038)$.

For the presentation of full profile information, a significant interaction with own gender was shown for the 25-min ride $(F(1,1424)=5.306, p=0.006)$ but not for the shorter ride of $14 \min (F(1,150)=0.848, p=0.430)$. As shown in Figure 6 (top right), for the longer ride, women showed higher WTA values when presented to a male full profile $(M=72.98$, $S D=19.80)$ than to a female full profile $(M=71.09, S D=20.26, F(1,91)=4.412, p=0.038)$.

\subsection{Cumulative Distribution}

The cumulative distribution of the WTA was used to assess the cost sensitivity of the respondents. The distribution function shows the share of respondents for a specific compensation demand (WTA). This information can be used to determine the WTA that is needed to attract a specific share of people, e.g., a critical mass of $90 \%$. As shown in Figure 7, the distribution varied depending on travel distance (left) and automation scenario (right). As the left Figure 7 shows, a 14-min ride required a lower discount $(50.00 \%)$ to attract the critical mass of $90 \%$ of respondents than a 25 -min ride $(62.22 \%)$.
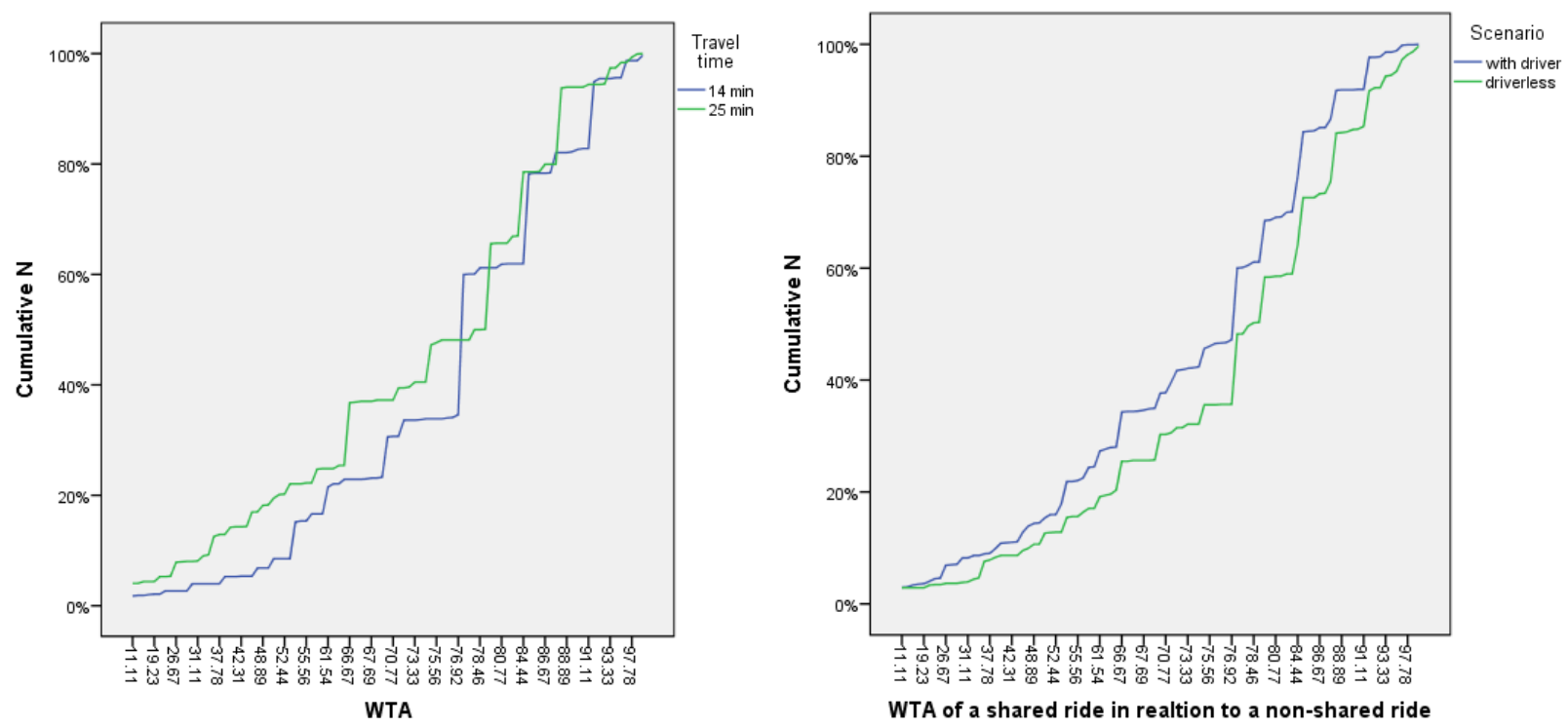

Figure 7. Cumulative distribution of the willingness to accept shared rides depending on the travel distance (left) and the degree of automation (right). The WTA of a shared rides is compared to WTA of the nonshared ride on the X-axis. Y-axis represents the distribution of the respondents.

Considering the effect of information on the cumulative distribution of respondents WTA, only slight tendencies were recognizable. As shown in Figure 8, the lowest discount needed to attract $90 \%$ of the respondents, as indicated by the highest maximum accepted costs was found under condition full female profile information. A critical mass of $90 \%$ of the respondents would share a ride if the price for the shared ride is $48.89 \%$ of the nonshared ride's price under this condition. In order to attract a critical mass of $90 \%$ of study participants, the maximum price accepted for a shared ride should be only $35.56 \%$ of the original price under condition male name. 


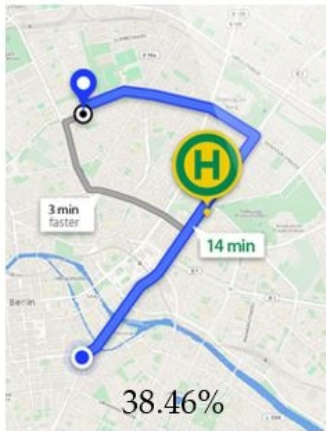

bus stop sign

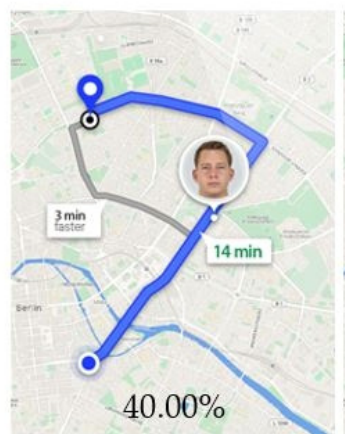

male picture

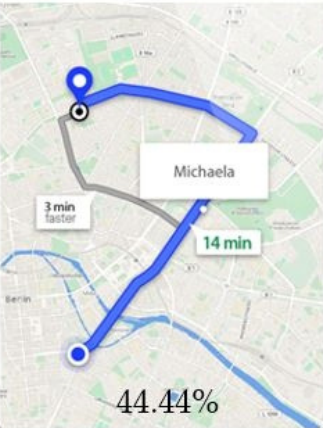

female name

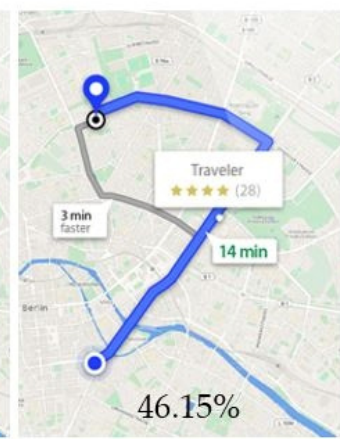

rating

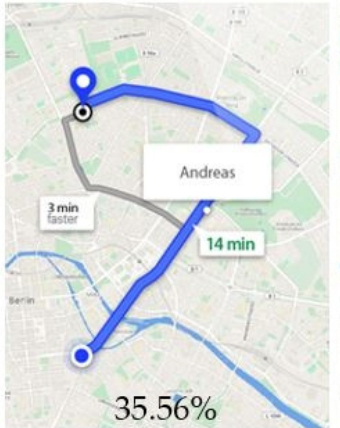

male name

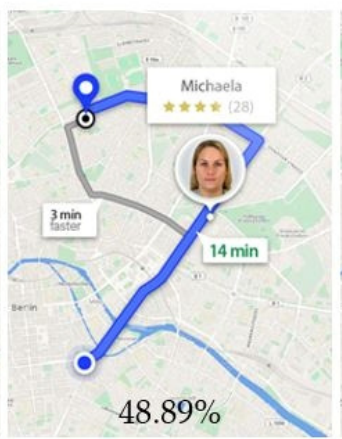

full female profile information

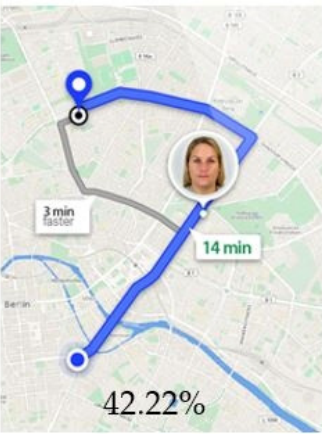

female picture

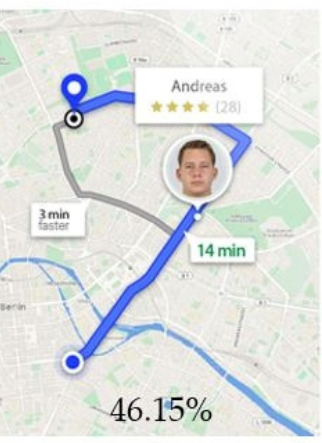

full male profile information

Figure 8. Maximum accepted price of a shared ride compared to a nonshared ride by a critical mass of $90 \%$ of participants depending on the information degree and the gender of the fellow passenger.

\section{Discussion}

\subsection{Summary and Interpretation of Findings}

It was shown that participants of the study revealed a high willingness to share rides in SAMODSs as indicated by a low overall refusal rate. The overall WTA for the shared rides as a measure of the compensation demands was nearly three quarters of the nonshared ride, indicating that regardless of the independent variables, the respondents required a reduction of approximately one quarter of the reference price.

Subsequently, the study findings are summarized by answering to the research questions concerned.

In terms of RQ1, the study found that the willingness to use SAMODSs was affected by the quality of information provided about fellow travelers. The likelihood of accepting a shared ride increases when more information is presented.

In more details, and to answer RQ2, the provision of detailed information about fellow travellers proved beneficial for reducing the compensation demands of travellers when sharing rides. Interestingly, the presentation of a name without further information on the fellow passenger decreased the willingness to share rides. The negative effect of the presentation of a name on the willingness to share rides was particularly relevant when male names were presented. The results are in line with the findings of Carol et al., (2019) who report a lower willingness to share a trip with male than female passengers for a ridesharing system [40]. They found strong indications for a discrimination of Turkish men in their study. Based on the result of the present study, the findings of [40] might be explained by the presentation of a name only. The provision of a rating proved relevant when looking at the cumulative distribution in terms of the maximum accepted costs of a shared ride (WTA) in relation to a nonshared ride. When a rating was presented, the lowest discount was needed to attract a critical mass of $90 \%$. The beneficial effect of a rating system has been emphasized in several studies concerning ridesharing and ridehailing systems $[39,57]$. Concerning the information presented on the gender of the 
fellow passenger, the study found that male gender information was related to a higher refusal rate than female gender information. This was particularly relevant when only names were presented. A further statistical analysis revealed a correlation between the presented gender information under the condition name and full profile information and the respondents' own gender for men but not for women. Apparently, the above-mentioned negative effect of the presentation of a male name can be traced back to an interaction with the respondent's own gender in a way that men require higher compensation for rides with other male travelers when only name information were provided. Regarding RQ3, the effect of autonomous driving on the travelers' willingness to share rides could not be conclusively assessed based on the presented study results. Contrary to prior expectations, the study found no clear effect of the degree of vehicle automation on the willingness to share rides in SAMODSs as proposed by [10]. The study revealed a strong tendency towards the direction that participants that envisioned a ride in the driverless vehicle required less compensation for sharing rides compared to a conventional system with driver.

With regard to RQ4, the rejection rate of shared rides in SAMODSs was higher and correspondingly the required compensation demands were higher for longer rides as has been expected based on findings of prior studies [7,31]. However, the results are in contrast to the findings of Lavieri and Bhat (2018), who found the willingness to share trips in SAMODSs to be independent of travel time [10]. They propose that the willingness to share represents a fixed cost. However, the results of our analysis of the cumulative distribution of the WTA showed that the need for a price reduction increases with an increase in travel time.

\subsection{Limitations and Further Research Needs}

Several limitations have to be regarded for the interpretation of the study's findings. A first limitation of the study is related to the number of participants that requires a careful interpretation of the results. The authors thus recommend a validation of the findings based on different (e.g., other countries) and larger samples. A possible shortcoming emerges from the difficulty to create respondents' vision of the autonomous transport system even though they have not experienced the system before. One important limitation of the applied approach to use an online survey is therefore the challenge of ensuring a sufficient degree of immersion. Studies that use online surveys often report a limited external validity due to self-selection effects, among others $[21,42,58,59]$. As a means to face the challenge of immersion, the study used comprehensive explanation and a figural description of the transport systems. Furthermore, participants that did not remember the presented scenario correctly were excluded from further analysis. It may be an interesting starting point for future research to design experiments that mimic the travel experience in autonomous systems in a more realistic manner, like by using virtual reality [10] and naturalistic settings.

Based on the presented study, several new research questions are emerging. Because the study revealed a positive effect of the information provision concerning fellow passengers, further research is also needed to assess travelers' willingness to share personal data [60]. A comprehensive examination of privacy and safety concerns of existing pooled ride-hailing and ridesharing users may be a necessary step to design future autonomous mobility-on-demand-systems [10]. The guarantee of data security on the one hand, and the requirements for information provision about fellow passenger on the other hand, raises the question about registration requirements for users of SAMODSs. It might also be interesting to look at further incentive strategies to encourage sharing rides, like social nudges [61] or ecological framing [62].

\section{Conclusions}

A discrete choice experiment investigated the effect of providing information about the fellow passengers on the willingness to share trips in driverless autonomous mobilityon-demand systems. A discrete choice experiment assessed the potential of provided 
information on the participants' compensation demands for a shared ride. The analysis revealed a beneficial effect of detailed information about fellow travellers (picture, name and rating) for reducing the compensation demands of travellers. In contrast, the provision of a name only resulted in higher compensation demands. The study results could be used to design booking apps for shared mobility-on-demand systems that consider the users' needs concerning fellow passengers. Further research is needed to validate the results in further, more naturalistic settings and to examine travellers' willingness to share personal data.

Author Contributions: Conceptualization, A.K. and J.G.; methodology, A.K.; software, A.K.; validation, C.W. and A.K.; formal analysis, A.K. and C.W.; investigation, A.K.; resources, J.G.; data curation, A.K.; writing—original draft preparation, A.K.; writing-review and editing, C.W. and J.G.; visualization, A.K.; supervision, A.K.; project administration, J.G.; All authors have read and agreed to the published version of the manuscript.

Funding: This research received no external funding.

Institutional Review Board Statement: Ethical review and approval were waived for this study, due to the online set-up of the study.

Informed Consent Statement: Informed consent was obtained from all subjects involved in the study.

Data Availability Statement: Data will be provided upon request.

Conflicts of Interest: The authors declare no conflict of interest.

\section{References}

1. SAE International. Taxonomy and Definitions for Terms Related to Driving Automation Systems for On-Road Motor Vehicles J3016_201806. Available online: https://www.sae.org/standards/content/j3016_201806/ (accessed on 18 June 2021).

2. Arena, F.; Pau, G.; Collotta, M. A survey on driverless vehicles: From their diffusion to security. J. Internet Serv. Inf. Secur. 2018, 8, 1-19.

3. Greenblatt, J.B.; Shaheen, S. Automated vehicles, on-demand mobility, and environmental impacts. Curr. Sustain. Energy Rep. 2015, 2, 74-81. [CrossRef]

4. Trommer, S.; Kolarova, V.; Fraedrich, E.; Kröger, L.; Kickhöfer, B.; Kuhnimhof, T.; Lenz, B.; Phleps, P. Autonomous Driving-The Impact of Vehicle Automation on Mobility Behaviour. Project Report. 2016. Available online: http://www.ifmo.de/publications. html? $\mathrm{t}=45$ (accessed on 18 June 2021).

5. ITF/OECD. Urban Mobility System Upgrade. How Shared Self-Driving Cars Could Change City Traffic. Corporate Partnership Board Report. 2015. Available online: https:/ /www.itf-oecd.org/sites/default/files/docs/15cpb_self-drivingcars.pdf (accessed on 10 May 2021).

6. Campisi, T.; Severino, A.; Al-Rashid, M.A.; Pau, G. The Development of the Smart Cities in the Connected and Autonomous Vehicles (CAVs) Era: From Mobility Patterns to Scaling in Cities. Infrastructures 2021, 6, 100. [CrossRef]

7. World Economic Forum. Reshaping Urban Mobility with Autonomous Vehicles Lessons from the City of Boston. 2018. Available online: http://www3.weforum.org/docs/WEF_Reshaping_Urban_Mobility_with_Autonomous_Vehicles_2018.pdf (accessed on 2 April 2021).

8. Fraedrich, E.; Beiker, S.; Lenz, B. Transition pathways to fully automated driving and its implications for the sociotechnical system of automobility. Eur. J. Futures Res. 2015, 3. [CrossRef]

9. ITF/OECD. The Shared-Use City: Managing the Curb. Corporate Partnership Board Report. 2018. Available online: https: //www.itf-oecd.org/shared-use-city-managing-curb-0 (accessed on 9 May 2021).

10. Lavieri, P.S.; Bhat, C.R. Modeling Individuals' Willingness to Share Trips with Strangers in an Autonomous Vehicle Future. Technical Report 141, University Transportation Center at the University of Texas at Austin 2018. Available online: http: / / ctr.utexas.edu/wp-content/uploads/141.pdf (accessed on 9 May 2021).

11. Thomopoulos, N.; Givoni, M. The autonomous car-A blessing or a curse for the future of low carbon mobility? An exploration of likely vs. desirable outcomes. Eur. J. Futures Res. 2015, 3, 1-14. [CrossRef]

12. Tirachini, H.; Gómez-Lobo, A. Does ridesourcing increase or decrease vehicle kilometers traveled (VKT)? A simulation approach for the case of Santiago, Chile. Working paper. Univ. De Chile 2017. [CrossRef]

13. Beiker, S. Implementation of an Automated Mobility-on-Demand System. In Autonomous Driving; Maurer, M., Gerdes, J., Lenz, B., Winner, H.H., Eds.; Springer: Berlin/Heidelberg, Germany, 2016; pp. 277-295.

14. Mourad, A.; Puchinger, J.; Chu, C. Owning or sharing autonomous vehicles: Comparing different ownership and usage scenarios. Eur. Transp. Res. Rev. 2019, 11, 1-20. [CrossRef]

15. Dandl, F.; Hyland, M.; Bogenberger, K.; Mahmassani, H.S. Evaluating the impact of spatio-temporal demand forecast aggregation on the operational performance of shared autonomous mobility fleets. Transportation 2019, 46, 1975-1996. [CrossRef] 
16. Bösch, P.M.; Becker, F.; Becker, H.; Axhausen, K.W. Cost-based analysis of autonomous mobility services. Transp. Policy 2017, 64, 76-91. [CrossRef]

17. COWI; PTV Group. The Oslo study-How Autonomous Cars May Change Transport in Cities. Report. 2019. Available online: https://www.cowi.com/about/news-and-press/new-report-how-self-driving-transport-will-affect-the-oslo-region (accessed on 9 May 2021).

18. Shen, Y.; Zhang, H.; Zhao, J. Integrating shared autonomous vehicle in public transportation system: A supply-side simulation of the first-mile service in Singapore. Transp. Res. Part A Policy Pract. 2018, 113, 125-136. [CrossRef]

19. Spieser, K.; Treleaven, K.; Zhang, R.; Frazzoli, E.; Morton, D.; Pavone, M. Toward a systematic approach to the design and evaluation of automated mobility-on-demand systems: A case study in Singapore. In Road Vehicle Automation; Meyer, G., Beiker, S., Eds.; Springer: Berlin/Heidelberg, Germany, 2015; pp. 229-245.

20. König, A.; Bonus, T.; Grippenkoven, J. Analyzing Urban Residents' Appraisal of Ridepooling Service Attributes with Conjoint Analysis. Sustainability 2018, 10, 3711. [CrossRef]

21. Fraedrich, E.; Cyganski, R.; Wolf, I.; Lenz, B. User Perspectives on Autonomous Driving: A Use-Case-Driven Study in Germany; Technical Report: Arbeitsberichte 187; Geographisches Institut, Humboldt University: Berlin, Germany, 2016.

22. Salonen, A.O.; Haavisto, N. Towards Autonomous Transportation. Passengers' Experiences, Perceptions and Feelings in a Driverless Shuttle Bus in Finland. Sustainability 2019, 11, 588. [CrossRef]

23. Krueger, R.; Rashidi, T.H.; Rose, J.M. Preferences for shared autonomous vehicles. Transp. Res. Part C Emerg. Technol. 2016, 69, 343-355. [CrossRef]

24. Guo, J.; Susilo, Y.; Antoniou, C.; Pernestål Brenden, A. Influence of Individual Perceptions on the Decision to Adopt Automated Bus Services. Sustainability 2020, 12, 6484. [CrossRef]

25. Herrenkind, B.; Nastjuk, I.; Brendel, A.B.; Trang, S.; Kolbe, L.M. Young people's travel behavior-Using the life-oriented approach to understand the acceptance of autonomous driving. Transp. Res. Part D Transp. Environ. 2019, 74, 214-233. [CrossRef]

26. Wicki, M.; Guidon, S.; Becker, F.; Axhausen, K.W.; Bernauer, T. How technology commitment affects willingness to use AVs: Results from realistic mode choice experiment for a self-driving shuttle service. In Proceedings of the 19th Swiss Transport Research Conference (STRC 2019), Ascona, Switzerland, 15-17 May 2019.

27. Madigan, R.; Louw, T.; Dziennus, M.; Graindorge, T.; Ortega, E.; Graindorge, M.; Merat, N. Acceptance of Automated Road Transport Systems (ARTS): An adaptation of the UTAUT model. Transp. Res. Procedia 2016, 14, 2217-2226. [CrossRef]

28. Epprecht, N.; Von Wirth, T.; Stünzi, C.; Blumer, Y.B. Anticipating transitions beyond the current mobility regimes: How acceptability matters. Futures 2014, 60, 30-40. [CrossRef]

29. Roche-Cerasi, I. Public acceptance of driverless shuttles in Norway. Transp. Res. Part F Traffic Psychol. Behav. 2019, 66, 162-183. [CrossRef]

30. Nordhoff, S.; de Winter, J.; Madigan, R.; Merat, N.; van Arem, B.; Happee, R. User acceptance of automated shuttles in Berlin-Schöneberg: A questionnaire study. Transp. Res. Part F Traffic Psychol. Behav. 2018, 58, 843-854. [CrossRef]

31. König, A.; Grippenkoven, J. Travelers' Willingness to Share Rides in Autonomous Mobility on Demand Systems Depending on Travel Distance and Detour Factor. Travel Behav. Soc. 2020, 21, 188-202. [CrossRef]

32. Alemi, F.; Circella, G.; Handy, S.; Mokhtarian, P. What influences travelers to use Uber? Exploring the factors affecting the adoption of on-demand ride services in California. Travel Behav. Soc. 2018, 13, 88-104. [CrossRef]

33. Lavieri, P.S.; Garikapati, V.M.; Bhat, C.R.; Pendyala, R.M.; Astroza, S.; Dias, F.F. Modeling individual preferences for ownership and sharing of autonomous vehicle technologies. Transp. Res. Rec. J. Transp. Res. Board 2017, 2665, 1-10. [CrossRef]

34. Salonen, A.O. Passenger's subjective traffic safety, in-vehicle security and emergency management in the driverless shuttle bus in Finland. Transp. Policy 2018, 61, 106-110. [CrossRef]

35. Polydoropoulou, A.; Tsouros, I.; Thomopoulos, N.; Pronello, C.; Elvarsson, A.; Sigpórsson, H.; Dadashzadeh, N.; Stojmenova, K.; Sodnik, J.; Neophytou, S.; et al. Who Is Willing to Share Their AV? Insights about Gender Differences among Seven Countries. Sustainability 2021, 13, 4769. [CrossRef]

36. Shaheen, S.; Stocker, A.; Mundler, M. Online and app-based carpooling in France: Analyzing users and practices-A study of BlaBlaCar. In Disrupting Mobility; Springer: Berlin/Heidelberg, Germany, 2017; pp. 181-196.

37. Amirkiaee, S.Y.; Evangelopoulos, N. Why do people rideshare? An experimental study. Transp. Res. Part F 2018, 55, 9-24. [CrossRef]

38. Morales Sarriera, J.; Escovar Álvarez, G.; Blynn, K.; Alesbury, A.; Scully, T.; Zhao, J. To share or not to share: Investigating the social aspects of dynamic ridesharing. Transp. Res. Rec. J. Transp. Res. Board 2017, 2605, 109-117. [CrossRef]

39. Nielsen, J.R.; Hovmøller, H.; Blyth, P.L.; Sovacool, B.K. Of "white crows" and "cash savers:" A qualitative study of travel behavior and perceptions of ridesharing in Denmark. Transp. Res. Part A Policy Pract. 2015, 78, 113-123. [CrossRef]

40. Carol, S.; Eich, D.; Keller, M.; Steiner, F.; Storz, K. Who can ride along? Discrimination in a German carpooling market. Popul. Space Place 2019, 25, e2249. [CrossRef]

41. Chaube, V.; Kavanaugh, A.L.; Perez-Quinones, M.A. Leveraging social networks to embed trust in rideshare programs. In Proceedings of the 2010 43rd Hawaii International Conference on System Sciences (HICSS), Honolulu, HI, USA, 5-8 January 2010.

42. Bansal, P.; Kockelman, K.M. Forecasting Americans' long-term adoption of connected and autonomous vehicle technologies. Transp. Res. Part A Policy Pract. 2017, 95, 49-63. [CrossRef] 
43. Siddiqi, Z; Buliung, R. Dynamic ridesharing and information and communications technology: Past, present and future prospects. Transp. Plan. Technol. 2013, 36, 479-498. [CrossRef]

44. Capasso da Silva, D.; Astroza, S.; Batur, I.; Khoeini, S.; Magassy, T.B.; Pendyala, R.M.; Bhat, C.R. Are Millennials Really All That Different Than Generation X? An Analysis of Factors Contributing to Differences in Vehicle Miles of Travel; Technical Paper; Department of Civil, Architectural and Environmental Engineering, The University of Texas at Austin: Austin, TX, USA, 2019.

45. Louviere, J.J.; Flynn, T.N.; Carson, R.T. Discrete choice experiments are not conjoint analysis. J. Choice Model. 2010,3 , 57-72. [CrossRef]

46. Chang, L.Y.; Lin, D.J.; Huang, C.H.; Chang, K.K. Analysis of contributory factors for driving under the influence of alcohol: A stated choice approach. Transp. Res. Part F Traffic Psychol. Behav. 2013, 18, 11-20. [CrossRef]

47. Gkartzonikas, C.; Gkritza, K. What have we learned? A review of stated preference and choice studies on autonomous vehicles. Transp. Res. Part C Emerg. Technol. 2019, 98, 323-337. [CrossRef]

48. Kyriakidis, M.; Happee, R.; de Winter, J.C. Public opinion on automated driving: Results of an international questionnaire among 5000 respondents. Transp. Res. Part F Traffic Psychol. Behav. 2015, 32, 127-140. [CrossRef]

49. Grutters, J.P.; Kessels, A.G.; Dirksen, C.D.; Van Helvoort-Postulart, D.; Anteunis, L.J.; Joore, M.A. Willingness to accept versus willingness to pay in a discrete choice experiment. Value Health 2008, 11, 1110-1119. [CrossRef]

50. Ma, D.S.; Correll, J.; Wittenbrink, B. The Chicago face database: A free stimulus set of faces and norming data. Behav. Res. Methods 2015, 47, 1122-1135. [CrossRef] [PubMed]

51. Leiner, D.J. SoSci Survey (Version 3.3.21) [Computer Software]. 2021. Available online: https://www.soscisurvey.de (accessed on 18 June 2020).

52. Bolton, R.N.; Parasuraman, A.; Hoefnagels, A.; Migchels, N.; Kabadayi, S.; Gruber, T.; Solnet, D. Understanding Generation Y and their use of social media: A review and research agenda. J. Serv. Manag. 2013, 24, 245-267. [CrossRef]

53. Federal Statistical Office. Einkommen, Konsum, Lebensbedingungen. Statistisches Jahrbuch 2019. Available online: https: / / www.destatis.de/DE/Themen/Querschnitt/Jahrbuch/jb-einkommenKonsumLeben.pdf?_blob=publicationFile (accessed on 29 May 2021).

54. Bates, D.; Mächler, M.; Bolker, B.; Walker, S. Fitting linear mixed-effects models using lme4. J. Stat. Softw. 2015, arXiv:1406.5823. [CrossRef]

55. Stroup, W.W. Generalized Linear Mixed Models: Modern Concepts, Methods and Applications; CRC Press: Boca Raton, FL, USA, 2012.

56. Snijders, T.; Bosker, R. Multilevel Analysis. An Introduction to Basic and Advanced Multilevel Modeling; Sage: London, UK, 2012.

57. Gargiulo, E.; Giannantonio, R.; Guercio, E.; Borean, C.; Zenezini, G. Dynamic ride sharing service: Are users ready to adopt it? Procedia Manuf. 2015, 3, 777-784. [CrossRef]

58. Alessandrini, A.; Alfonsi, R.; Delle Site, P.; Stam, D. Users' preferences towards automated road public transport: Results from European surveys. Transp. Res. Procedia 2014, 3, 139-144. [CrossRef]

59. Tussyadiah, I.P.; Zach, F.J.; Wang, J. Attitudes Toward Autonomous on Demand Mobility System: The Case of Self-Driving Taxi. Inf. Commun. Technol. Tour. 2017, 755-766. [CrossRef]

60. Schudy, S.; Utikal, V. 'You Must Not Know about Me'-On the Willingness to Share Personal Data. Munich Discussion Paper No. 2ß015-15. Department of Economics, University of Munich, 2015. Available online: http://epub.ub.uni-muenchen.de/25264/ (accessed on 21 March 2019).

61. Riggs, W. Painting the fence: Social norms as economic incentives to non-automotive travel behavior. Travel Behav. Soc. 2017, 7, 26-33. [CrossRef]

62. Avineri, E.; Waygood, E.O.D. Applying goal framing to enhance the effect of information on transport-related $\mathrm{CO}_{2}$ emissions. In Proceedings of the 9th Biennial Conference on Environmenal Psychology, Eindhoven, The Netherlands, 26-28 September 2011. 